\title{
GEORGE BERKELEY (1685-1753) (III)
}

\author{
MUNOA ROIZ JL ${ }^{1}$
}

La impresión primaria que se deriva de la lectura de estas obras de Berkeley es la de que niega la existencia del mundo exterior y lo reduce a un simple hecho subjetivo.

Sin embargo, un análisis más detenido permite comprender que no trata de disolver el mundo exterior y la materia en una sensación derivada de la percepción, sino de afirmar que, a nuestros ojos, el mundo exterior es, ante todo, una realidad psicológica y espiritual.

Las percepciones que constituyen nuestro mundo no son otra cosa que «el discurso que Dios mantiene con los hombres» por medio de la Naturaleza.

En el conjunto de su obra, Berkeley reitera un objetivo fundamental; interpretar la vida religiosa como un coloquio entre Dios y el hombre. Se trata del mensaje de un religioso a un colectivo apto para asumir la permanente tutela divina sobre la Creación.

La teoría empírica del conocimiento (Bacon, Locke) es así repensada y elevada a conciencia filosófica. El empirismo le permite a Berkeley eliminar el obstáculo representado por el mundo material.

La confusión entre la interpretación espiritualista y la fenomenista del sistema de Berkeley ha permitido emitir juicios tan sorprendentes como el de Lenin, que acusó a Ernst Mach (1838-1916), físico y filósofo austríaco, de «idealista» y de «discípulo de Berkeley». y por tanto, opuesto al materialismo propugnado por el marxismo.

Las veintiuna tesis que Karl R. Popper sintetiza del pensamiento de Berkeley, sorprenden por su modernidad. Son análogas a la filosofía de la Física de Ernest Mach y tuvieron una gran influencia en la física moderna, especialmente sobre la teoría de la relatividad. Estas tesis también presentan una gran semejanza con los «Principios de la mecánica»
(1894), de Heinrich Rudolph Hertz (1857-1894) y con el «Tractatus» de Ludwig Wittgenstein (18891951).

En resumen, la obra es un ensayo con el objetivo de reducir toda experiencia a experiencia interna y desplazar el contenido de la conciencia cognoscente. Así, es imposible concebir una cosa sensible separada o distinta de la percepción correspondiente.

Así, Popper afirma: «la navaja de Berkeley» es aún mas afilada que la de Guillermo de Occam, ya que éste prescindía totalmente de la realidad -metafísica y hasta meramente conceptual-, mientras que Berkeley erradica todas las entidades excepto las percibidas.

\section{BIBLIOGRAFÍA}

- Abbagnano, Nicolás. "Historia de la Filosofía». Vol. II. Pp. 270-278. Montaner y Simón. Barcelona. 1964.

- Berkeley, George. "Ensayo sobre una nueva teoría de la visión». Tra. M. Fuentes. Ed. Espasa Calpe Argentina. Buenos Aires. 1948. Ed. Aguilar. Madrid. 1965. "Principios del conocimiento humano». "Tres diálogos entre Hilas y Filonus». Folio. Barcelona. 2002.

- Ferrater Mora «Diccionario de Filosofía». Vol. I. Pp. 203-205. Editorial Sudamericana. Buenos Aires. 1965.

- Gregory. R.L. The intelligent Eye. pp. 11-12. World University. London. 1977.

- Gregory. R.L. Ojo y Cerebro. pp. 192-197. Ed. Guadarrama. Madrid. 1965.

- Geymonat. L. Historia de la Filosofía y de la Ciencia. Vol. II. pp. 241-245. Ed. Critica. Barcelona. 1985.

- Heaton J.M. The Eye. pp.43-156. Tavistock Pub. Lippincot Comp. London. 1968.

- Hirschberg Julius. The History of Ophthalmology. Vol 4. (part two) p.297. Bonn. 1984.

- Hondderich Ted (Compilador). «Los Filósofos». Historia del Pensamiento. La Ilustración. Geoffrey Warnock. Vol. 4. pp. 10-17. Ed. Sarpe. Madrid 1988. 
- Huisman Denis. Diccionario de las mil obras clave del pensamiento. pp.230. Ed. Tecnos. Madrid 1997.

- Idroyd David «El arco del conocimiento». Pp. 163-170. Ed. Crítica. Barcelona. 1993.

- Popper K.R. Conjeturas y refutaciones. Nota sobre Berkeley como precursor de Mach y Einstein. cap. 6. pp. 20822218. Paidos Ibérica. Barcelona 1991.

- Reale.G. y Antiseri. D. Historia del pensamiento filosófico y científico. Vol. II. pp. 453-455. Ed. Herder. Barcelona. $2^{a}$. Ed. 1992.

- Zeky. Semir. A Vision of the Brain. pp. 214-216. Blackwell Scientific Pub. Oxford. 1993

\section{Ronald Knox}

There was a young man who said, "God

Must think it exceedingly odd if $\mathrm{He}$ finds that this tree continues to be

When there's no one about in the Quad"
Dear Sir:

Your astonishment's odd:

I am always about in the Quad.

And that's why the tree

Will continue to be, Since observed by Yours faithfully

GOD.

- Roland Arbuthnot Hilary Knox (1888-1957).

Hijo de A.E. Knox obispo de Manchester y hermano de «Evoe» editor de «Punch».

Muy dado a la controversia religiosa, ingresó en la Iglesia Católica en 1917 y fue nombrado capellán de postgraduados en Oxford en 1926.

Defensor del individualismo religioso, fue un prolífico escritor acerca de temas religiosos. 